\title{
A STUDY OF ANISOTROPY BENEATH GREAT BRITAIN USING THE POLARIZATIONS OF TELESEISMIC SHEAR-WAVES RECORDED BY BGS/UKNET
}

\author{
Masataka Ando, ${ }^{*}$ Stuart Crampin, ${ }^{* *}$ David C. Booth, ${ }^{* *}$ \\ and David REDMAYNE** \\ * Disaster Prevention Research Institute, Kyoto University, \\ Uji, Japan \\ ** British Geological Survey, Murchison House, \\ West Mains Road, Edinburgh EH9-3LA, Scotland, UK
}

(Received March 6, 1987; Revised February 18, 1988)

\begin{abstract}
The directions of the polarizations of the leading shear-wave, recorded by the United Kingdom seismometer network (UKNET) of the British Geological Survey, have been analyzed to investigate the anisotropic structure beneath the United Kingdom. Fifty-nine short-period and seventeen long-period records from 15 intermediate and deep earthquakes, mainly from the northwestern Pacific area, were used to identify the polarization directions. The short-period shear-waves show polarization directions primarily scattered around the polarization directions of long-period (about $20 \mathrm{~s}$ ) shear-waves. Since such long-period shear-waves can preserve the polarization directions radiated at the source fixed by the geometry and orientation of the focal mechanism, the short-period polarization directions are primarily the same as the source polarization directions. This can be interpreted as indicating that anisotropy beneath the UK, if it exists, is weak and not uniformly aligned, and is localized possibly into several blocks.
\end{abstract}

\section{Introduction}

Anisotropy has been increasingly recognized in the Earth's crust and upper mantle. Beginning with Hess in 1964, many seismological observations have now shown the presence of seismic anisotropy in the upper mantle and more recently in the crust. There are two major data sources for studies of upper-mantle anisotropy: seismic velocities of both body and surface waves and station residuals measured over path lengths of more than $100 \mathrm{~km}$; and geophysical and petrological laboratory measurements of seismic velocities and mineral alignments in ophiolite and nodules from the upper mantle. Among these studies are: 1) seismological data (HEss, 1964; RAITt et al., 1969; SCHLue and KNOPOFF, 1976; CRAmpin and KING, 1977; DZIEWONSKI and ANDERSON, 1981) and 2) petrographic data (PESELNICK and Nicolas, 1978; Nicolas et al., 1980; Christensen and LundQuist, 1982; 
Christensen, 1984). Combining these two kinds of information, many mineral alignment models of upper mantle anisotropy have been presented (HEss, 1964; Francis, 1969; Ave'Lallemant and CarTER, 1970; FuCHS, 1977). In these models it is commonly assumed that the upper mantle is uniformly anisotropic from handspecimen size upwards until the seismic velocity changes are averaged out by long seismic wavelengths. If the upper-mantle anisotropy is as uniform as these models suggest, seismic shear-waves propagating through the mantle should show splitting (bi-refringence, or double refraction).

However, the assumption of uniform anisotropy is questioned by recent analyses of structure. The structure in the upper mantle appears to be heterogeneous, not only in active tectonic regions (e.g., Hirahara, 1977; HoriE et al., 1984), but also stable continents (AKI et al., 1976; ROMANOwICZ, 1980). It should be also noted that the upper mantle structure is not anisotropic everywhere (e.g., BAMFORD et al., 1979; ANDO et al., 1983). Seismic anisotropy of the upper mantle, therefore, is expected to be at least partly heterogeneous or absent. Analysis of shear-wave splitting should be able to demonstrate the existence or absence of the anisotropy and the uniformity or heterogeneity of it.

Theoretical and numerical studies show that shear-wave splitting is a diagnostic feature of propagation through an anisotropic medium (CRAMPIN, 1977, 1981; KeITH and CRAmPIN, 1977). The anisotropy can be investigated by analyzing splitting in individual three-component shear-wave arrivals. Splitting is believed to be a reliable and effective way to survey anisotropy in the upper mantle. Upon entry into an anisotropic medium, a shear-wave necessarily splits into phases (usually two if the anisotropy is weak) with different polarizations and different velocities. Since the split shear-waves propagate with different velocities and polarizations, the shear-wave splits, the usually linear particle motion of the incident shear-wave is lost, and a characteristic signature appears in the three-component shear wavetrain. This phenomenon of shear-wave polarization anomalies is diagnostic of propagation through some form of effective anisotropy, and can be used to evaluate the anisotropy along the ray path. Since the two split shear-waves follow similar ray paths through heterogeneities in the crust and mantle, it is expected that such lateral and vertical heterogeneities usually disturb shear-wave splitting less than they do Pwave velocity-anisotropy. Numerical experiments with synthetic seismograms appear to support this assertion (CRAMPIN, 1981).

The British Isles appear to be an appropriate place to investigate anisotropy in a stable upper-mantle as it has been free from orogenic activity for more than 200 m.y. and the geological structure of the upper mantle is expected to be simpler than presently active tectonic areas such as Japan. The British Geological Survey has recently developed a suitable seismometer network (UKNET) covering most of Britain which records continuously on analogue magnetic tape (BRowITT, 1979). The network currently includes 12 three-component sites. Analyzing shear-wave splitting requires three-component instrumentation and the necessary timing accuracy makes recording on magnetic tape essential. This paper interprets seismic 
anisotropy beneath the UK by using the polarizations of teleseismic shear-waves from deep events recorded by UKNET.

\section{Method of Analysis}

Our primary purpose is identifying polarization anomalies in incident shearwaves resulting from propagation through the anisotropy beneath the stations. Since at least four factors control the behaviour of shear-wave polarizations at the free surface, we need to identify the cause of any effects we see. These factors are:

1) the effects of the interaction with the free surface;

2) the radiation from the source (focal mechanism);

3) possible inhomogeneities along the ray path; and

4) the anisotropy along the ray path.

We shall show that these effects can be eliminated or identified by the following considerations.

Shear-waves recorded at a free surface are modified by the interactions with the surface (e.g., NutTli, 1960; MENDiguren, 1969). Incident shear-waves are free from this distortion only when the angle of incidence at the surface is less than a critical angle $\sin ^{-1}\left(V_{\mathrm{S}} / V_{\mathrm{P}}\right)$. This is about $35^{\circ}$ for a Poisson's ratio of 0.25 . Recently, further analysis of the effects of free surface on shear-waveforms have been made by BOOTH and CRAMPIN (1985). We restrict our analysis to teleseismic sources with an epicentral distance greater than $30^{\circ}$ (Table 1 ), where the angle of incidence should be within the critical angle. Thus, the shear-waves used in this study should be free from free-surface distortions.

An earthquake source radiates shear-waves with polarizations which are fixed at the source by the geometry and orientation of the focal mechanism. These polarizations will be generally preserved at a receiver, if the shear-waves propagate through a homogeneous isotropic structure. Thus, one way to investigate anisotropy would be to determine the focal mechanism of the earthquakes and base the interpretation on the polarizations radiated from the origin. Here, we shall base the interpretation on the polarizations of the long-period shear-waves as discussed below.

Structural discontinuities, and blocks of material with different anisotropic symmetries along the ray path, could result in complicated waveforms caused by splitting, phase interference, and mode conversion. The study of polarization anisotropy on the basis of teleseismic records imposes several problems: 1) ray paths are long and the incidence angles to layer boundaries are changed significantly during the propagation, leading to difficulties in locating the relevant anisotropy; 2) significant phase changes may occur at interfaces with large impedance contrasts. Nevertheless, the polarization of the faster shear-wave is a local phenomenon controlled by the symmetry of the anisotropy near the recording site. Thus, the initial polarization of the first arrival depends only on the symmetry of the last anisotropic region the ray traversed. 


\section{Data}

We use data from three-component records of UKNET with a natural pendulum period of $1 \mathrm{~s}$. The location of the 12 three-component stations used in this study are shown in Fig. 1 and their parameters are listed in Table 1 (TURBITT, 1984). The hypocentral parameters of the teleseismic events used in this study are listed in Table 2, and their epicentres are shown in Fig. 2. The events, with magnitudes greater than $m_{\mathrm{b}}=5.6$ and depths below $70 \mathrm{~km}$, were selected from the Bulletin of the International Seismological Centre, and the United States Geological Survey, Preliminary Determination of Epicenters. Firstly, 160 seismograms from 55 earthquakes for the period between January 1978 and April 1984 were identified. Secondly, 60 shear-wave arrivals of S or SKS were identified on seismograms of

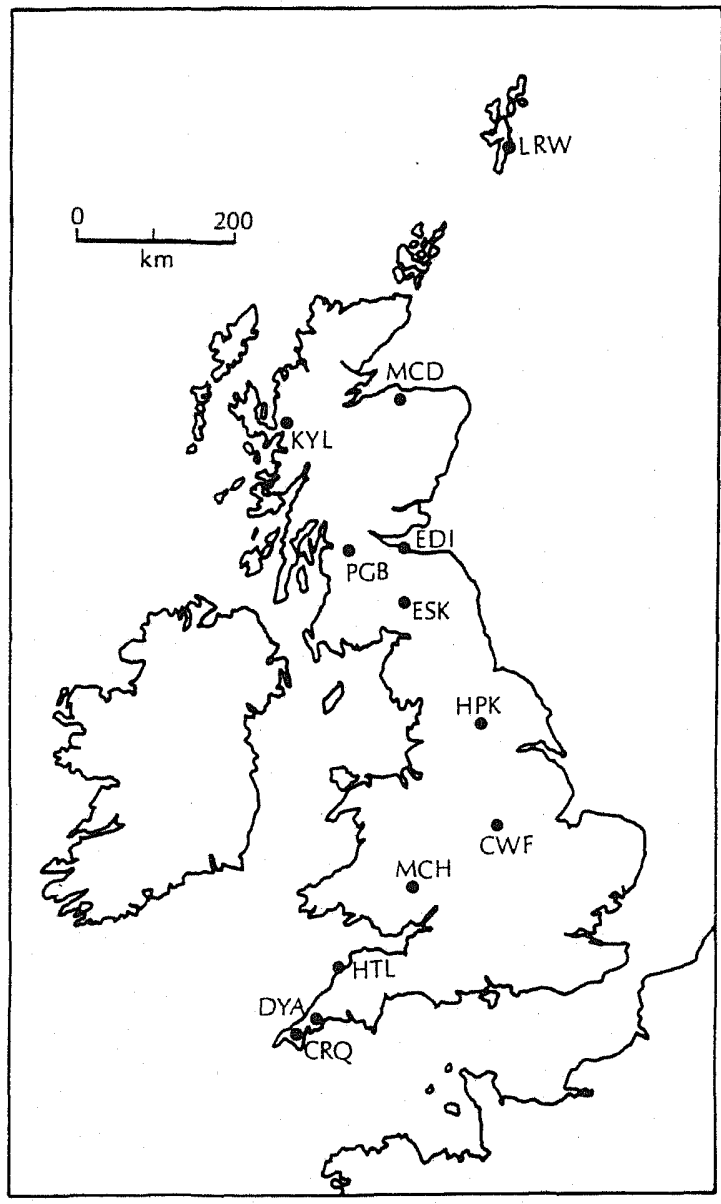

Fig. 1. Three-component seismograph stations of the UKNET used in this study. 
Table 1. Three-component seismograph stations of UKNET used in this study.

\begin{tabular}{lllccc}
\hline Code & $\begin{array}{c}\text { Lat } \\
(\mathrm{N})\end{array}$ & $\begin{array}{c}\text { Lon } \\
(\mathrm{W})\end{array}$ & $\begin{array}{c}\text { Opened } \\
\text { date }\end{array}$ & $\begin{array}{c}\text { Closed } \\
\text { date }\end{array}$ & $\begin{array}{c}\text { Type of } \\
\text { seismometer }\end{array}$ \\
\hline ESK & 55.3167 & 3.2050 & $\begin{array}{c}12 / 65- \\
4 / 81-\end{array}$ & $\begin{array}{c}\text { WWSSN } \\
\text { MK3 }\end{array}$ \\
KYL & 57.3196 & 5.6506 & $11 / 78-$ & MK3 \\
EDI & 55.9233 & 3.1861 & $1969-$ & $8 / 12 / 81$ & MK3 \\
MCH & 51.9977 & 2.9983 & $8 / 2 / 78-$ & $4 / 4 / 82$ & MK3 \\
HPK & 53.9554 & 1.6240 & $1978-$ & & MK3 \\
CWF & 52.7382 & 1.3071 & $1975-$ & MK3 \\
LRW & 60.1360 & 1.1779 & $2 / 9 / 78-$ & MK3 \\
MCD & 57.5827 & 3.2541 & $26 / 6 / 81-$ & MK3 \\
CRQ & 50.1672 & 5.1728 & $1981-$ & MK3 \\
HTL & 50.9944 & 4.4850 & $11 / 2 / 81-$ & & MK3 \\
DYA & 50.4352 & 3.9309 & $24 / 4 / 82-$ & & MK3 \\
PGB & 55.810 & 4.478 & $2 / 84$ & MK3 \\
\hline
\end{tabular}

MK3 refers to the Willmore Mark 3.

Table 2. Hypocentral parameters* used in this study.

\begin{tabular}{rccccccl}
\hline No. & Date & Time & Lat & Lon & Depth & $m_{\mathrm{b}}$ & Region \\
\hline 1 & 17 Mar. 1978 & $02: 48: 47.6$ & $31.99 \mathrm{~N}$ & $137.61 \mathrm{E}$ & 441 & 6.5 & Honshu \\
2 & 21 June 1978 & $11: 10: 38.7$ & $48.27 \mathrm{~N}$ & $148.66 \mathrm{E}$ & 380 & 5.8 & NW of Kurile \\
3 & 28 May 1979 & $09: 27: 33.9$ & $36.46 \mathrm{~N}$ & $031.72 \mathrm{E}$ & 111 & 5.8 & Turkey \\
4 & 17 Oct. 1979 & $05: 43: 03.1$ & $18.49 \mathrm{~N}$ & $145.39 \mathrm{E}$ & 601 & 6.1 & Marianas \\
5 & 23 Nov. 1979 & $23: 40: 29.7$ & $04.81 \mathrm{~N}$ & $076.20 \mathrm{~W}$ & 105 & 6.3 & Colombia \\
6 & 11 Dec. 1979 & $17: 26: 18.5$ & $28.95 \mathrm{~N}$ & $140.94 \mathrm{E}$ & 126 & 6.2 & Bonin Island \\
7 & 27 Nov. 1981 & $17: 21: 44.3$ & $42.93 \mathrm{~N}$ & $131.19 \mathrm{E}$ & 525 & 5.7 & USSR-China \\
8 & 22 June 1982 & $04: 18: 40.5$ & $7.34 \mathrm{~S}$ & $126.04 \mathrm{E}$ & 450 & 6.3 & Banda Sea \\
9 & 04 Apr. 1983 & $02: 51: 34.3$ & $5.72 \mathrm{~N}$ & $94.72 \mathrm{E}$ & 79 & 6.6 & Sumatra \\
10 & 21 Dec. 1983 & $12: 05: 06.3$ & $28.19 \mathrm{~S}$ & $63.17 \mathrm{~W}$ & 602 & 6.2 & Argentina \\
11 & 30 Dec. 1983 & $23: 52: 39.9$ & $36.37 \mathrm{~N}$ & $70.74 \mathrm{E}$ & 215 & 6.6 & Hindu Kush \\
12 & 01 Feb. 1984 & $07: 28: 28.7$ & $49.06 \mathrm{~N}$ & $146.59 \mathrm{E}$ & 573 & 5.9 & Okhotsk \\
13 & 06 Mar. 1984 & $02: 17: 21.2$ & $29.38 \mathrm{~N}$ & $138.94 \mathrm{E}$ & 457 & 6.2 & Honshu \\
14 & 23 Apr. 1984 & $21: 40: 35.5$ & $47.45 \mathrm{~N}$ & $146.69 \mathrm{E}$ & 414 & 6.0 & Kuril \\
15 & 24 Apr. 1984 & $04: 11: 29.0$ & $30.91 \mathrm{~N}$ & $138.43 \mathrm{E}$ & 403 & 6.1 & Honshu \\
\hline
\end{tabular}

* From Bulletin of the International Seismological Centre (1978-1981) and from the Preliminary Determination of Epicentres of the USGS National Earthquake Information Service (1982--1984).

these events. In general, it was found that earthquakes with $m_{\mathrm{b}}<6.0$ radiated smallamplitude short-period S or SKS waves. Signals from these events can only be used when the signal-to-noise ratio is large enough. The signals on the analogue magnetic tapes were digitized at every $0.04 \mathrm{~s}$, and played out as seismogram traces and polarization diagrams drawn for two-second time windows.

Figure 3 shows some examples of three-component seismograms and their 




Fig. 2. Azimuthal-equidistant projection of epicenters of the earthquakes used in this study and of the location of ESK, the WWSSN station in Great Britain.

polarization diagrams from event 14 . The arrows indicate the arrivals and directions of the polarizations of the first shear-waves. The polarization diagrams are numbered corresponding to the 2-s time-intervals marked over the traces. The diagrams in each time-interval are normalized separately. Figure 3(a) to (d) show that azimuths of the polarizations of the leading shear-waves are $42^{\circ}$ at EDI, $90^{\circ}$ at ESK, $60^{\circ}$ at $\mathrm{HPK}$, and $90^{\circ}$ at HTL. The polarization diagrams at EDI show a relatively linear horizontal motion for the first $1 \mathrm{~s}$ of shear-wave arrived. The diagram at ESK shows a clear westward motion for the first $1 \mathrm{~s}$ until the second shear-wave arrives with almost orthogonal polarization. The particle-motion at HPK is elliptical and the orientation of the first shear-wave is taken to be parallel to the first half cycle of the motion as shown in Fig. 3(c) (indicated by the arrow

Fig. 3. Typical seismograms and polarization diagrams from event 14 in Table 2, recorded by four stations: (a) EDI, (b) ESK, (c) HPK, and (d) HTL. The polarization diagrams are numbered corresponding to the 2-s time-intervals marked above the seismograms. The diagrams are, from the top, the Up-Down and North-South projection, Up-Down and East-West, and the horizontal projection. The diagrams in each time interval have been normalized separately, and the figure below each box shows the relative amplifications. The arrows on the horizontal projection of the $\mathrm{S}$ wave mark the arrival and orientation of the leading shear-wave. 

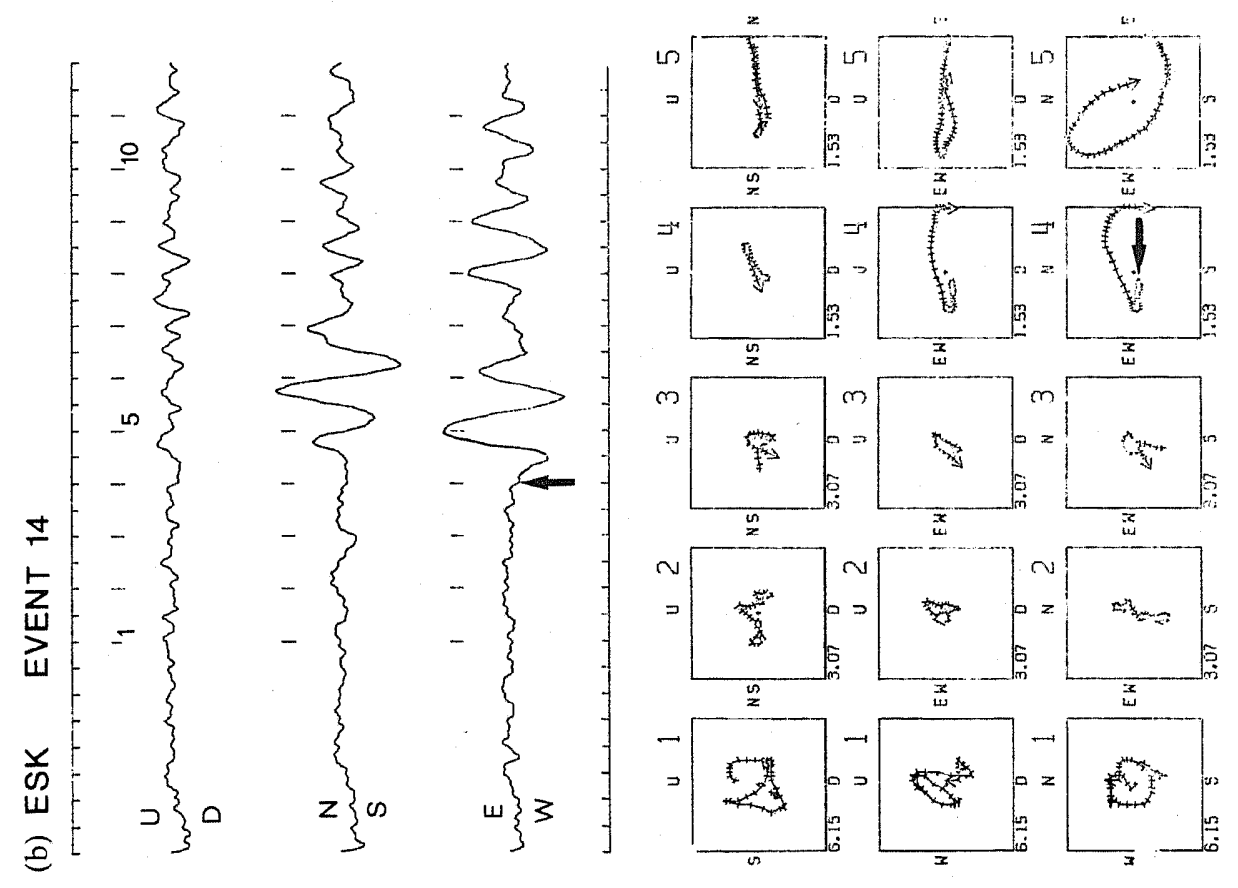

m
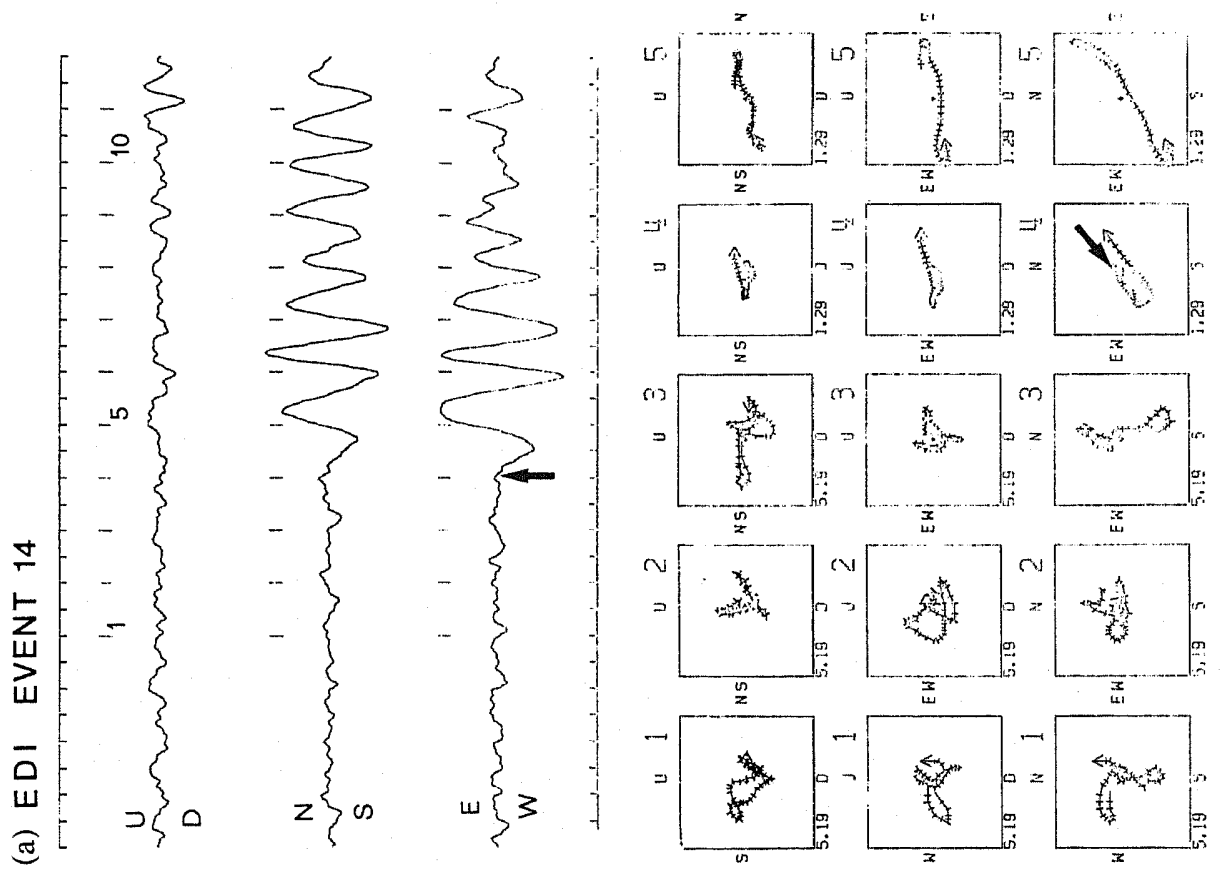

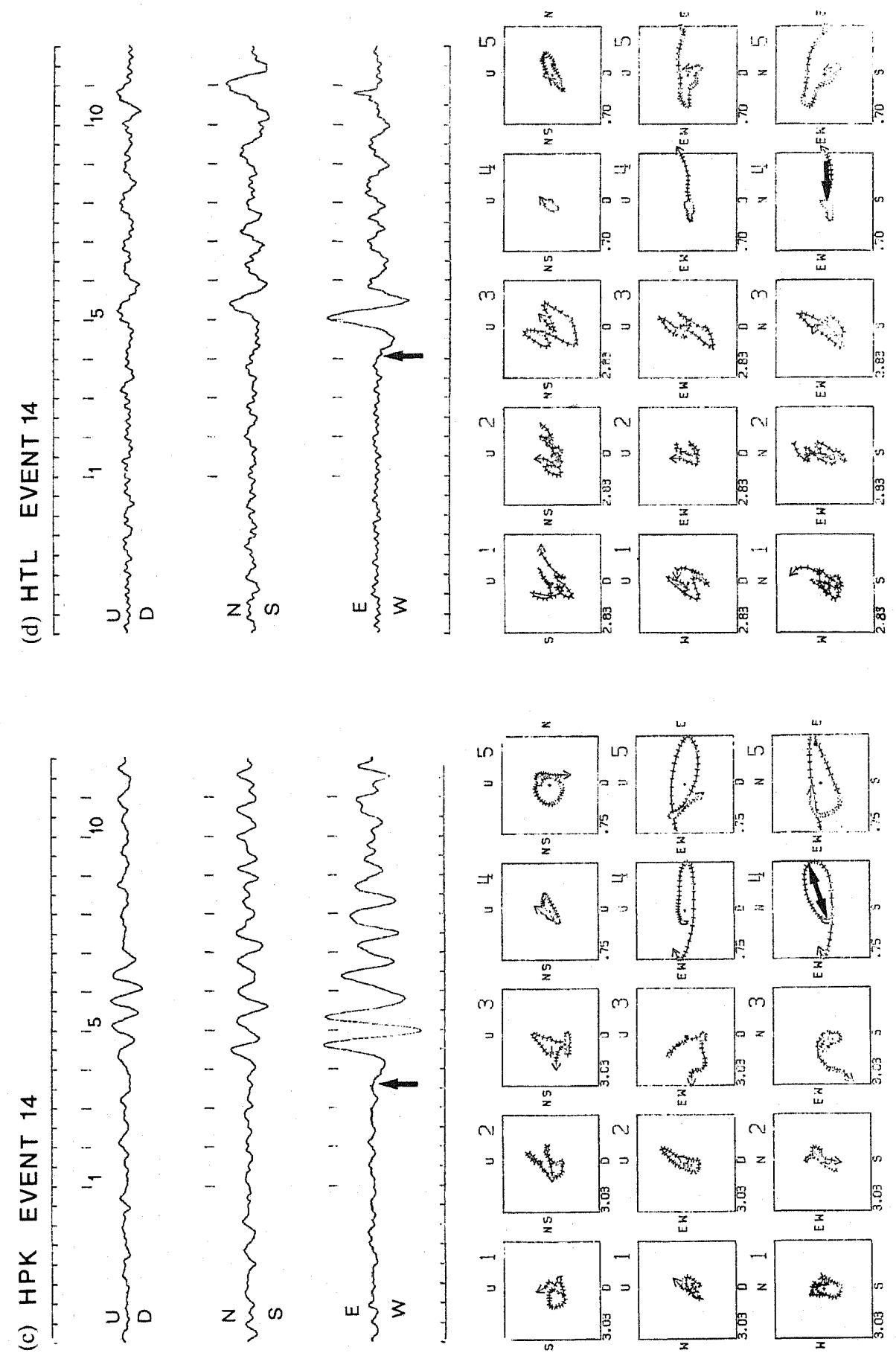
with two heads). The shear-waves at HTL are impulsive and show a $1 \mathrm{~s}$ delay between the shear-wave arrivals on the two horizontal components.

The first shear-wave arrival can be identified unambiguously on the majority of seismograms. To recognize the effects of personal bias in measurements, the arrivals and polarization directions on all the recordings were read by two people independently. Although some large discrepancies were found, the average error in the measurements of the shear-wave polarization orientation is less than $5^{\circ}$, which is negligible in the study of teleseismic shear-wave polarizations. However, some signals were measured by one reader but rejected by the other, and vice versa, because of the ambiguous shear-waveforms.

Estimates of the polarization directions of the shear-wave arrivals were made for the earthquakes in Table 2. The polarization directions are plotted on equal-area projections in Fig. 4 and listed in Table 3. The polarizations show some parallel alignments at $\mathrm{HPK}, \mathrm{MCD}$, and $\mathrm{MCH}$, but show wide scatter at the other stations. There are not many polarizations observed at each station and they cover only part of the equal-area plot within the shear-wave's critical angle. Any pattern in the symmetry, which is suitable for the Earth's interior, is difficult to identify in the projections in Fig. 4. Although orientations of the polarizations of the split shear-
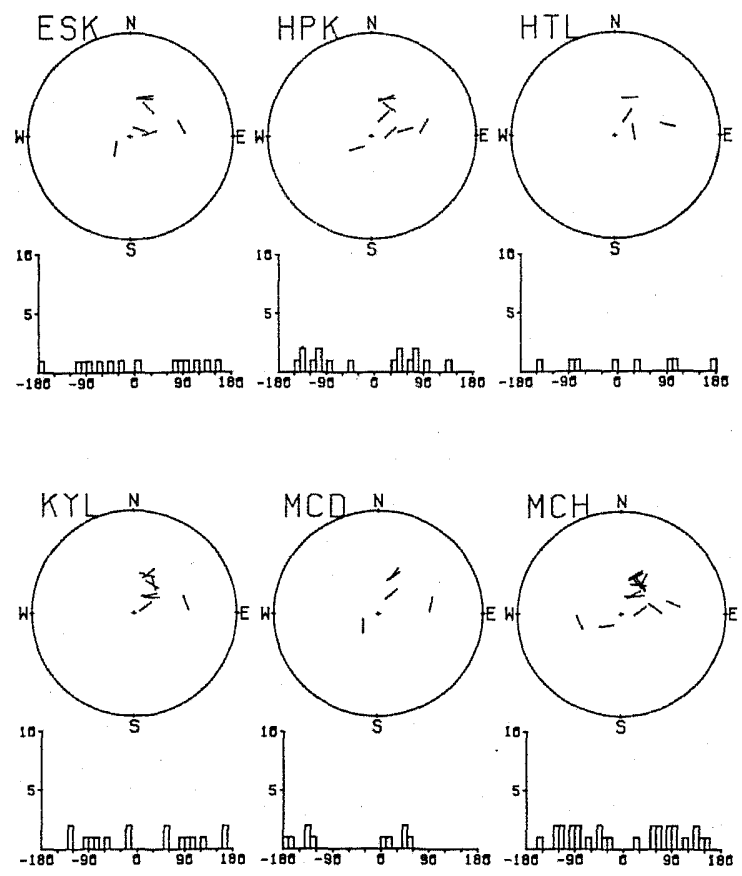

Fig. 4. Orientations of the polarizations of the first shear-wave arrivals observed at six stations of the UKNET and those combined for all the stations. The upper diagrams are equal-area projections. The lower diagrams are histograms of the observed orientations at each station for directions East of North. 
Table 3. Orientations of the first arrival shear-waves.

\begin{tabular}{|c|c|c|c|c|c|c|c|c|c|c|c|c|c|c|c|c|}
\hline No. & $\mathrm{D}$ & $\mathrm{Az}$ & $\mathrm{i}$ & Phs & LP & CRQ & CWF & DYA & EDI & ESK & HPK & HTL & KYL & $\mathrm{MCD}$ & $\mathrm{MCH}$ & PGB \\
\hline 1 & 87 & 33 & 17 & $\mathrm{~S}$ & -60 & - & - & - & - & - & - & - & -15 & - & -37 & - \\
\hline 2 & 74 & 19 & 19 & SKS & -60 & - & - & - & - & - & - & - & -77 & - & - & - \\
\hline 3 & 30 & 114 & 28 & $\mathrm{~S}$ & 27 & - & - & - & 48 & - & - & - & - & - & - & - \\
\hline 4 & 102 & 30 & 16 & $\mathrm{~S}$ & 41 & - & - & - & - & - & + & - & - & - & -85 & - \\
\hline 5 & 76 & 258 & 20 & $S$ & -18 & - & - & - & 0 & - & - & - & - & - & -23 & - \\
\hline 6 & 90 & 31 & 10 & SKS & 41 & - & - & - & -28 & - & + & - & - & - & 90 & - \\
\hline 7 & 75 & 33 & 19 & $\mathrm{~S}$ & 39 & - & - & - & - & - & + & - & - & - & 28 & - \\
\hline 8 & 117 & 60 & 6 & SKS & 45 & + & - & 64 & 76 & -70 & - & + & 51 & + & - & - \\
\hline \multirow[t]{2}{*}{9} & 90 & 80 & 16 & $\mathrm{~S}$ & -67 & + & + & - & - & + & 75 & + & - & - & 86 & - \\
\hline & 90 & 80 & 9 & SKS & 78 & + & + & - & - & 70 & + & -10 & - & - & 51 & - \\
\hline 10 & 98 & 230 & 9 & SKS & 50 & + & 75 & - & 90 & 8 & 72 & + & + & 0 & 80 & - \\
\hline 11 & 52 & 79 & 25 & $\mathrm{~S}$ & -32 & -20 & 18 & - & -50 & -28 & 30 & -75 & -20 & 12 & -65 & - \\
\hline 12 & 73 & 20 & 20 & $\mathrm{~S}$ & 45 & + & - & -77 & - & 82 & - & + & 50 & 40 & 58 & - \\
\hline 13 & 89 & 32 & 16 & $S$ & -54 & - & - & + & 30 & + & -50 & + & -58 & - & + & - \\
\hline 14 & 74 & 21 & 19 & $S$ & 67 & -67 & - & - & 42 & 90 & 60 & 90 & - & 56 & 62 & 90 \\
\hline \multirow[t]{2}{*}{15} & 88 & 32 & 16 & $\mathrm{~S}$ & -55 & - & - & - & - & -45 & + & + & - & + & -42 & -41 \\
\hline & 88 & 32 & 11 & SKS & 32 & 17 & - & - & - & 23 & 45 & 33 & - & 48 & 60 & 56 \\
\hline
\end{tabular}

No., Event number corresponding to that in Table 2; D, epicentral distance; Az, azimuth of station to epicenter; i, incidence angle of shear-wave to the earth's surface; Phs, phase used; S or SKS; and LP, orientation of the first arrival of the long-period shear-wave observed at ESK. The values of D and Az shown are all for ESK, but can be used for other stations within an error of 30 . -, Three-component seismogram recorded with a proper instrumental response is not available or station was not in operation. + , Difficult to determine the polarization direction because of its complicated waveform. 
waves change rapidly with direction and incidence angle near nodal lines where the faster and slower shear-wave velocities are almost identical (e.g., Fig. 5 in CRAMPIN and MCGONIGLE, 1981), this interpretation is probably not applicable to these scattered patterns in Fig. 4. The irregular patterns suggest that anisotropy beneath the receivers is not uniform or is very weak beneath Great Britain.

\section{Comparison with Long-Period Polarizations}

The polarization of the leading shear-waves from short-period teleseismic events are scattered. We investigate the causes of the scatter and discuss the source polarizations. The mechanisms of the earthquakes used in this study are available in a series of papers by Dziewonski and his co-workers (e.g., DzIEwonskr et al., 1981, 1983, and others). However, the orientation of the shear-wave polarization changes rapidly around the stress axes of the double-couple mechanism, and large discrepancies may be expected in the estimate of the radiated shear-wave polarizations from comparatively minor inaccuracies in the focal parameters. Hence, we use the polarization of the long-period shear-wave measured on long-period seismograms recorded at ESK (the WWSSN station in UK) to estimate the source radiation. We read trace amplitudes of S and SKS phases on long-period NS and EW components of each shear-wave arrival. We checked for phase distortions and delays between the two components, and found no signs of such discrepancies: the onset of two component $S$ waves are identical within a possible reading accuracy of $2 \mathrm{~s}$ on the long-period seismograms as shown in Fig. 5. Since S waves on the WWSSN longperiod seismograms of the events used in this study are 10 to $20 \mathrm{~s}$ in period, phase distortions in the seismograms would not be obvious even if a possible delay of $2 \mathrm{~s}$ exists. The horizontal particle-motion of such a wave is a flat ellipse with its long axis oriented approximately parallel to the polarization of the incident shear-wave from the upper mantle beneath receivers. The polarizations of eleven $\mathrm{S}$ and five SKS phases with a suitable signal-to-noise ratio are measured on the long-period seismograms as shown in Table 3. The polarizations of the five SKS phases are very close (within $15^{\circ}$ ) to the azimuths from the epicentre to the stations. The polarization of the SKS of Event 15 is assumed to be parallel to the azimuth from station to epicenter as its small amplitude makes an accurate estimate impossible (Fig. 5). Since the SKS has only a radial component in an isotropic spherical structure, this consistency supports the assumption that the polarizations observed on the long-period S and SKS are consistent with the source mechanism. This agrees with the results of numerical experiments by CORMIER (1984) that realistic threedimensional isotropic structures will rarely generate a derivation of more than $10^{\circ}$ in the orientation of the $S$ polarization vector compared to a radially homogeneous Earth.

Figure 6 shows maps of polarization orientations of the first shear-wave arrivals from short-period and long-period records for the four events, where the short-period polarizations can be read at more than five stations. In Fig. 6, the thick 


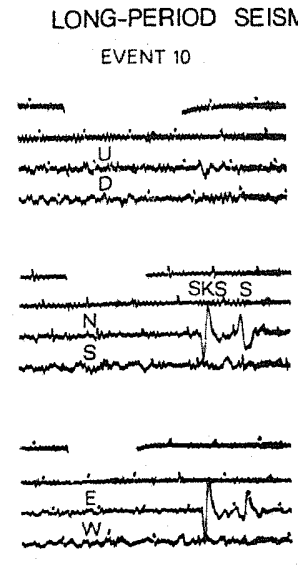

(a)

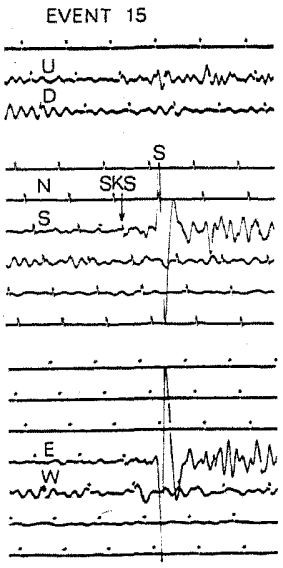

(b)

Fig. 5. Long-period shear-waves at ESK: (a) event 10 , and (b) event 15 , the amplitude of the $S$ phase is small on both components to determine the polarization direction, but the NS component is apparently larger than the EW one. This suggests that the assumption of $\mathrm{N} 33^{\circ} \mathrm{E}$ for the polarization could be reasonable.

lines with letters LP are oriented in the direction of the polarization of the longperiod shear-wave at ESK and other thick lines at station positions denote that the particle-motion is nearly linear. This near-linear particle-motion suggests either: (1) one of the polarizations of the two split shear-waves permitted by the symmetry of the anisotropy is parallel to the polarization of the radiated shear-wave, or (2) the arrival-time difference (delay) between the two split shear-waves is small.

The following are brief comments on the observed polarizations:

a) Event 14: Four short-period polarizations are parallel and three nearly parallel to the long-period directions. The general trend of the short-period polarizations is a rotation of $10^{\circ}$ to $20^{\circ}$ counter-clockwise from the long-period polarization direction.

b) Event 15: This earthquake is the only event where both S and SKS waves can be measured at several stations. The polarization direction of the long-period SKS cannot be determined precisely because of the small trace amplitude (Fig. 5(a)), but it appears to be approximately parallel to the azimuth to the epicenter, $\mathrm{N} 32^{\circ} \mathrm{E}$, and is, thus, near orthogonal to the LP S-wave polarization. Thus, the short-period polarization directions of the SKS phase are nearly parallel to the long-period polarizations. The short-period polarizations of the $\mathrm{S}$ phase can be determined at two stations; their directions are oblique to the direction of the SKS and parallel to the long-period S-wave polarization that is accurately determined on the basis of large trace amplitudes (Fig. 5(b)). 




Fig. 6. Orientations of the polarization of the first SP shear-wave arrivals from teleseismic earthquakes observed at UKNET and those of the polarization of LP arrivals for: (a) event 14 , (b) event 15 , (c) event 10 , (d) event 11 ; thick bars at stations indicate approximately linear SP particle-motion. Arrows indicate azimuth of arrival.

c) Event 10: The particle-motions of the short-period waves at the southernmost stations are nearly linear and parallel to the LP motion. The northernmost stations show oblique directions at short $45^{\circ}$ to the LP motion.

d) Event 11: The short-period polarizations at three stations are nearly parallel to the long-period polarizations and are nearly linear. The directions at HPK and CWF, where the particle-motions are complicated, differ from the longperiod directions by about $40^{\circ}$. These complications are probably due to crustal reverberations.

The above comparison suggests that the polarization direction of the short- 


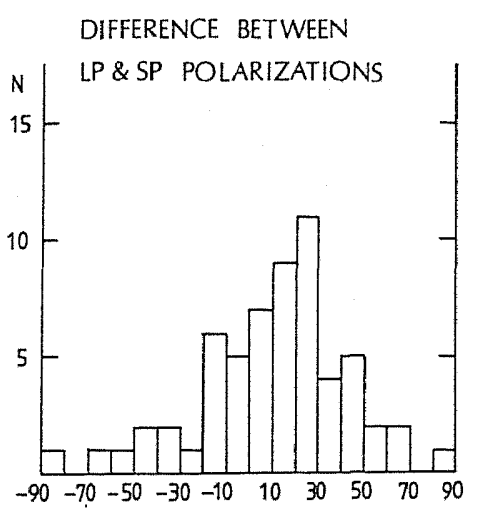

Fig. 7
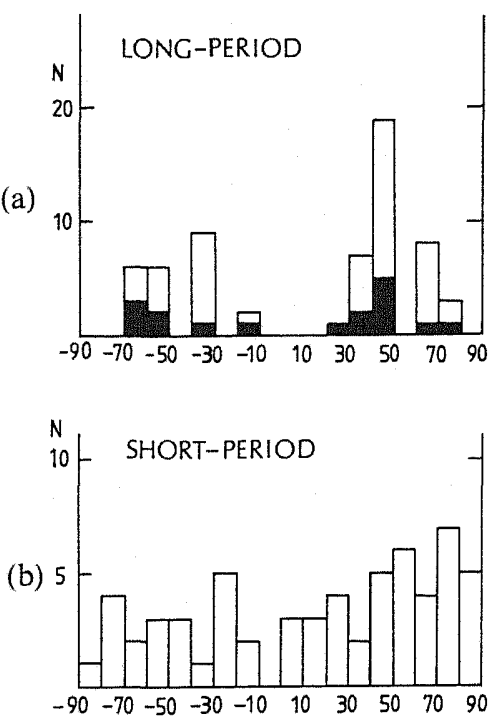

Fig. 8

Fig. 7. The cumulative distribution of the differences of the short-period polarizations with respect to the long-period observations at ESK. The best-fit normal-distribution curve with the mean and variance of $15^{\circ}$ and $30^{\circ}$, respectively, is also shown.

Fig. 8. (a) The cumulative distribution of the orientations of long-period shearwave polarizations at ESK for earthquakes, measured East of North (open plot), and the cumulative distribution of the number of stations whose observed polarization can be determined (solid plot). (b) The cumulative distribution of short-period polarizations observed at all the stations.

period shear-wave are primarily the same as the long-period shear-waves. To confirm this, we further compare polarizations of the long-period and the shortperiod shear-waves as follows. We subtract the orientation of the polarization of the leading short-period shear-wave from that of the polarization of the long-period shear-wave recorded at ESK. The deviations between the two polarizations are plotted with an interval of $10^{\circ}$ in Fig. 7. The plot suggests an almost normal distribution with a mean of $10^{\circ}$ and a variance of $30^{\circ}$. This implies that the shortperiod polarizations observed at the UKNET are primarily controlled by the polarization of shear-waves radiated from the sources.

It should be noted that the mean of the distribution curve in Fig. 7 is not zero. This might reject the hypothesis that the homogeneous distribution of scatterers causes the observed distribution of deviations between the short-period and longperiod polarization angles. Figure 8(a) shows the cumulative distribution of the observed long-period polarization directions: (1) the solid plot representing the cumulative distribution of long-period polarizations at ESK for the earthquakes 
and (2) the open plot the cumulative distribution of the number of stations whose observed short-period polarizations can be determined. The cumulative distribution of the long-period polarizations in (2) that would have been observed at the stations has two broad peaks: $40^{\circ}$ to $60^{\circ}$, and $-30^{\circ}$ to $-70^{\circ}$. Figure $8(\mathrm{~b})$ shows cumulative distribution of short-period polarizations in each $10^{\circ}$ interval. The frequency of the short-period polarization in the negative range scatters around the peak of the longperiod distribution, but in the positive range it increases towards $90^{\circ}$ with a peak between $70^{\circ}$ and $90^{\circ}$ rather than around the peak of long-period polarizations. The numbers of the short-period polarization orientations between $70^{\circ}$ and $90^{\circ}$ are significantly different from the expected distribution. Out of 12 points between $70^{\circ}$ and $90^{\circ}$ in Fig. 8(b), eight points fall in a range of $10^{\circ}$ and $30^{\circ}$ in deviation between short-period and long-period polarizations. If we take these points away from Fig. 7 , the distribution in Fig. 7 would become close to a normal distribution with a mean of $0^{\circ}$. These points are the main contribution which moves the peak away from $0^{\circ}$ in Fig. 7.

\section{Discussion}

We list some of the features in the comparison of the short-period polarizations recorded at UKNET with the long-period polarizations at the WWSSN long-period seismograms at ESK:

1) The short-period polarizations primarily scatter around the orientation of the long-period polarizations.

2) The deviation between the polarizations of the short-period and the longperiod shear-waves is in a normal distribution with a mean of about $10^{\circ}$ and a variance of about $30^{\circ}$.

3) The cumulative number of orientations in the range between $70^{\circ}$ and $90^{\circ}$ of short-period polarizations is more than that expected from the distribution of orientations of the long-period polarizations.

4) The fluctuations in the deviation between the short-period and the longperiod polarizations are large even for the same earthquakes.

As summarized above, large-scale anisotropy has not been found beneath the UK with a method using shear-wave polarization anomaly. This apparent absence of anisotropy is consistent with the results by BAMFORD et al. (1979) who analyzed several refraction surveys in the North Sea and northern Scotland and concluded that $\mathrm{Pn}$-wave anisotropy is not measurable for the structure of this area within the limits of observational accuracy.

If the anisotropy of the continental lithosphere remains a feature which is locked-in after it has developed, the anisotropy of continental margins may be as complicated as its history of superimposed tectonic processes. The anisotropy in this case would reflect paleo-flow patterns rather than the present flow one in a lithosphere-asthenosphere boundary layer once the plate has cooled and thickened. This could be a possible interpretation for the scattering distribution of directions of 
the short-period shear-wave polarizations. As a matter of fact the British Isles developed under a complicated history as the continental margins on the Atlantic ocean (WILSON, 1966).

\section{Conclusions}

Fifty-nine teleseismic seismograms from 15 earthquakes have been investigated to try to estimate anisotropy in the upper mantle beneath Great Britain. Directions of the first shear-wave arrivals are measured on two horizontal component seismograms recorded at the 12 three-component stations of the UK network. The comparison of these short-period polarization directions with the long-period polarization directions recorded at ESK, the WWSSN station, suggest that directions of short-period and long-period shear-waves are usually parallel. This implies that anisotropy if it exists beneath the UK is weak and is not uniformly aligned, and is localized possibly into several blocks.

The work of MA was supported by the Study Abroad Program of the Japan Society for the Promotion for Science. The work of SC, DCB, and DR was supported by the National Environment Research Council and is published with the approval of the Director of the British Geological Survey (NERC).

\section{REFERENCES}

Aki, K., A. Christofferson, and E. S. Husebye, Three-dimensional seismic structure of the lithosphere under Montana Lasa, Bull. Seismol. Soc. Am., 66, 501-524, 1976.

ANDO, M., Y. ISHIKAWA, and Y. YAMAZAKI, Shear wave polarization anisotropy in the upper mantle beneath Honshu, Japan, J. Geophys. Res., 88, 5850-5864, 1983.

Ave'Lallemant, H. G. and N. L. CarTer, Syntectonic recrystallization of olivine and modes of flow in the upper mantle, Geol. Soc. Am. Bull., 81, 2203-2220, 1970.

BAMFord, D., Pn velocity anisotropy in a continental upper mantle, Geophys. J. R. Astron. Soc., 49, 29-48, 1983.

Bamford, D., M. JentsCh, and C. Prodehl, Pn anisotropy studies in northern Britain and in the eastern and western United States, Geophys. J. R. Astron. Soc., 57, 397-429, 1979.

Booth, D. C. and S. CRAmpin, Shear-wave polarizations on a curved wavefront at an isotropic free-surface, Geophys. J. R. Astron. Soc., 83, 31-45, 1985.

BrowitT, C. W. A., Seismograph networks of the Institute of Geological Sciences, UK, Phys. Earth Planet. Inter., 18, 127-134, 1979.

CHRISTENSEN, N. I., The magnitude, symmetry and origin of upper mantle anisotropy based on fabric analyses of ultramafic tectonites, Geophys. J. R. Astron. Soc., 76, 89-111, 1984.

Christensen, N. I. and S. M. Lundquist, Pyroxene orientation within the upper mantle, Bull. Geol. Soc: Am., 93, 279-288, 1982.

CORMier, V. F., The polarization of S waves in a heterogeneous isotropic Earth model, $J$. Geophys., 56, 20-23, 1984.

CRAMPIN, S., A review of the effects of anisotropic layering of the propagation of seismic waves, Geophys. J. R. Astron. Soc., 49, 9-27, 1977. 
CRAmpIN, S., A review of wave motion in anisotropic and cracked elastic media, Wave Motion, 3, 343-391, 1981.

CRAMPIN, S. and D. W. KING, Evidence for anisotropy in the upper mantle beneath Eurasia from the polarization of higher mode seismic surface waves, Geophys. J. R. Astron. Soc., 49, 59-85, 1977.

CRAmpIn, S. and R. MCGonigle, The variation of delays in stress-induced anisotropic polarization anomalies, Geophys. J. R. Astron. Soc., 64, 115-131, 1981.

DzIEwonski, A. M. and D. L. Anderson, Preliminary reference Earth model, Phys. Earth Planet. Inter., 25, 297-356, 1981.

DzIEWONSKI, A., T.-A. ChoY, and J. H. WoOdhouse, Determination of earthquake source parameters from waveform data for studies global and regional seismicity, J. Geophys. Res., 86, 2825-2852, 1981.

Dziewonski, A. M., A. Friedman, D. Giardini, and J. H. WoOdhouse, Global seismicity of 1982: Centroid-moment tensor solutions for 308 earthquakes, Phys. Earth Planet. Inter., 33, 76-90, 1983.

FRANCIS, T. J. G., Generation of seismic anisotropy in the upper mantle along the midoceanic ridges, Nature, 221, 162-165, 1969.

FucHs, K., Seismic anisotropy of the subcrustal lithosphere as evidence for dynamical processes in the upper mantle, Geophys. J. R. Astron. Soc., 31, 93-118, 1977.

Hess, H. H., Seismic anisotropy of the uppermost mantle under oceans, Nature, 203, 629$631,1964$.

HIRAHARA, K., A large-scale three-dimensional seismic structure under the Japan islands and the Sea of Japan, J. Phys. Earth, 25, 393-417, 1977.

HORIE, A., H. IsHII, and A. TAKAGI, Fine structure beneath the Tohoku district, northeastern Japan arc, as derived by an inversion of P-wave arrival times from local earthquakes, Tectonophysics, 101, 245-265, 1984.

KeITH, C. M. and S. CRAMPIN, Seismic body waves in anisotropic media: synthetic seismograms, Geophys. J. R. Astron. Soc., 49, 225-243, 1977.

Mendiguren, J. A., Study of mechanisms of deep earthquakes in Argentina using non-linear particle motion of S-waves, Bull. Seismol. Soc. Am., 59, 1449-1473, 1969.

NiCOLAS, A., F. BOUDIER, and J. L. BOUCHEZ, Interpretation structures from ophiolitic and oceanic environments, Am. J. Sci., 280A, 192-210, 1980.

NUTTLI, O., The effect of the Earth's surface on the S wave particle motion, Bull. Seismol. Soc. Am., 51, 237-246, 1960.

Peselnick, L. and A. Nicolas, Seismic anisotropy in an ophiolite peridotite: Application to oceanic upper mantle, J. Geophys. Res., 83, 1227-1235, 1978.

RaItT, R. W., G. G. Shor, T. J. G. Francis, and G. B. Morris, Anisotropy of the Pacific upper mantle, J. Geophys. Res., 74, 3095-3109, 1969.

Romanowicz, A. B., A study of large-scale lateral variation of $\mathrm{P}$ velocity in the upper mantle beneath western Europe, Geophys. J. R. Astron. Soc:, 63, 217-232, 1980.

SCHLUE, J. W. and L. KNOPOFF, Shear wave anisotropy in the upper mantle of the Pacific Basin, J. Geophys. Res. Lett., 3, 359-362, 1976.

TurbitT, T. (ed.), Catalogue of British earthquakes recorded by the BGS seismograph network 1979, 1980, 1981, Brit. Geol. Sur., GSU Rep., 210, 1984.

WILSON, J. T., Did the Atlantic close and then re-open?, Nature, 214, 676-681, 1966. 